\title{
Role of Big Data in Decision Making
}

\author{
Shirish Jeble \\ Faculty of Management \\ IBS Business School, Pune, India \\ Email: shirish.jeble@gmail.com (Corresponding Author) \\ Sneha Kumari \\ Symbiosis Center for Research and Innovation \\ Symbiosis International University, Pune, India \\ Email: snehakumari1201@gmail.com \\ Yogesh Patil \\ Symbiosis Center for Research and Innovation \\ Symbiosis International University, Pune, India
}

\begin{abstract}
Information systems coupled with internet, cloud computing, mobile devices and Internet of Things have led to massive volumes of data, commonly referred as big data. It includes mix of structured, semi-structured and unstructured real-time data, constituting of data warehouse, OLAP, ETL and information. Business firms and academicians have designed unique ways of tapping value from big data. There is a great scope of using large datasets as an additional input for making decisions. The aim of the paper is to explore the role of big data in these areas for making better decisions. Here we explore how big data can be used to make smart and real-time decisions for improving business results. The paper undergoes literature review and secondary data to provide a conceptual overview of potential opportunities of big data in decision making. The paper discusses the concept of big data, its role in decision making and also the competitive advantage of big data for different firms. The paper also discusses a framework for managing data in decision making. The topic must be addressed for taking better decisions for firms which will contribute to high quality knowledge.
\end{abstract}

Keywords: big data, big data analytics, social media analytics, marketing analytics

\section{INTRODUCTION}

Information systems have evolved over the years from being transactions recording system to supporting business decisions at different levels. Traditional information systems depended primarily on internal data sources such as enterprise resource planning systems (ERPs) for making business decisions. These datasets were structured and used relational database management system (RDBMS). These were used for supporting internal business decisions such as inventory management, pricing decisions, finding out most valuable customers, identifying loss making products etc. Besides, data warehouse was built using this data for analysis and mining purpose. These data sources were integrated with data from business partners such as suppliers and customers using enterprise application integration (EAI) platforms. EAI enabled seamless integration of information systems between business partners. It enhanced speed of business to business transactions (B2B), communication and reduced cost of inter-company transactions.

In the next wave in early nineties, arrival of internet further simplified integration of firms with their business partners. In the last decade, information systems coupled with internet, cloud computing, mobile devices and Internet of Things have led to massive volumes of data, commonly referred as big data. It includes structured, semi-structured and unstructured real-time data, constituting of data warehouse, OLAP, ETL and information. Computer science has advanced to store and process large volumes of diverse datasets using statistical techniques. Business firms and academicians have designed unique ways of tapping value from big data. The objective of this paper is to explore the role of big data in making better decisions and how big data can be used to make smart and real-time decisions for improving business results.

The revolution of big data is more powerful than the analytics which were used in the past. Using big data helps managers to make better decisions on the basis of evidences rather than intuition. Businesses are collecting more data than required for any use (McAfee et al., 2012); big data helps in making better predictions and smarter decisions. Leaders across industries use big data for better managerial practices. There are several researches conducted in individual areas such as transactional data, social media data, supply chain big data etc. However, there is lack of holistic review of understanding potential of big data for decision makers. Driven by this need we explore the role of variety of big data in various decision-making scenarios. This paper acts as a bridge this gap by achieving the following objectives:

a) To explore the existing literature on the fundamental concepts of big data and its role in decision making

b) To explore role of big data in making strategic, tactical and operational decisions.

The study is useful for making important decisions with the help of big data. In the present era, big data has been used 
in many business and educational sectors. This has led to make better predictions and better decisions.

In the next section, we review extant literature on big data and how it is gaining significance for business and society. Here we have reviewed several definitions of big data from leading big data and analytics professionals. We also touch upon different ways in which applications of analytics can be classified. Third section discusses various applications and benefits of big data. Here we review how different institutions such as banks or business firms have been able to collect, analyze and use big data for enhancing their business performance.

Role of Analytics based decision making using big data is nothing new for some of the leading companies. However, there are still many small and medium size companies which can start taking advantage of this emerging field. In the fourth section, we present a framework on big data that can be used by such companies. This framework could be a starting point to refine the model suitable for their businesses. Finally, in the last section we conclude our study with our findings and suggest future research directions.

\section{LITERATURE REVIEW}

In this section, we review the extant literature which provides various ways in which firms are using big data for analysis and decision making. After defining the objectives of our research, we identified keywords such as 'Big Data', 'Big Data and Decision Making' and 'Big Data Analytics'. We searched through research papers in top journals, conference papers and web sources and shortlisted relevant papers. Good quality research papers have been selected through Scopus, Science Direct and Google Scholar database. The identified keywords have been typed in the database and papers relevant to the topic have been selected. Figure 1 shows the number of papers per year published in various journals.

\subsection{What is Big Data?}

Big data has been defined in several ways by several authors. Boyd and Crawford (2012) have defined big data as cultural, technological and scholarly phenomenon while Fan et al. (2014) have defined big data as the ocean of information. According to Kitchin (2014), big data is defined as huge volume of structured and unstructured data. Waller $\&$ Fawcett (2013) define big data as datasets that are too large for traditional data processing systems and therefore require new technologies to process them. Dubey et al. (2015) describe it as the traditional enterprise machine generated data and social data. Big data is a term that describes the large volume of data - both structured and unstructured - that inundates a business on a day-to-day basis. But it's not the amount of data that's important. It is what organizations do with the data that matters. Big data can be analyzed for insights that lead to better decisions and strategic business moves.

According to Dyche (2014), the concept of big data for many people is just millions of data which can be analyzed through technologies. Big data in true sense is the proper use of data through technologies in any particular aspect. Big data evolved in the first decade of the $21^{\text {st }}$ century embraced first by the online and startup firms. A new type of data voice, text, log files, images and videos have come into existence (Davenport and Dyche, 2013). The proper use of big data results in several applications of big data helping in decision making.

Various techniques and tools enhance the decisionmaking ability. Firms such as Amazon, Netflix have developed algorithms to find out correlation between customer searches, past purchase history to predict which products customer is likely to buy. Customers are reminded about their past searches or recommended products based on their purchase history. This creates opportunity of customers buying some of the recommended products thereby boosting

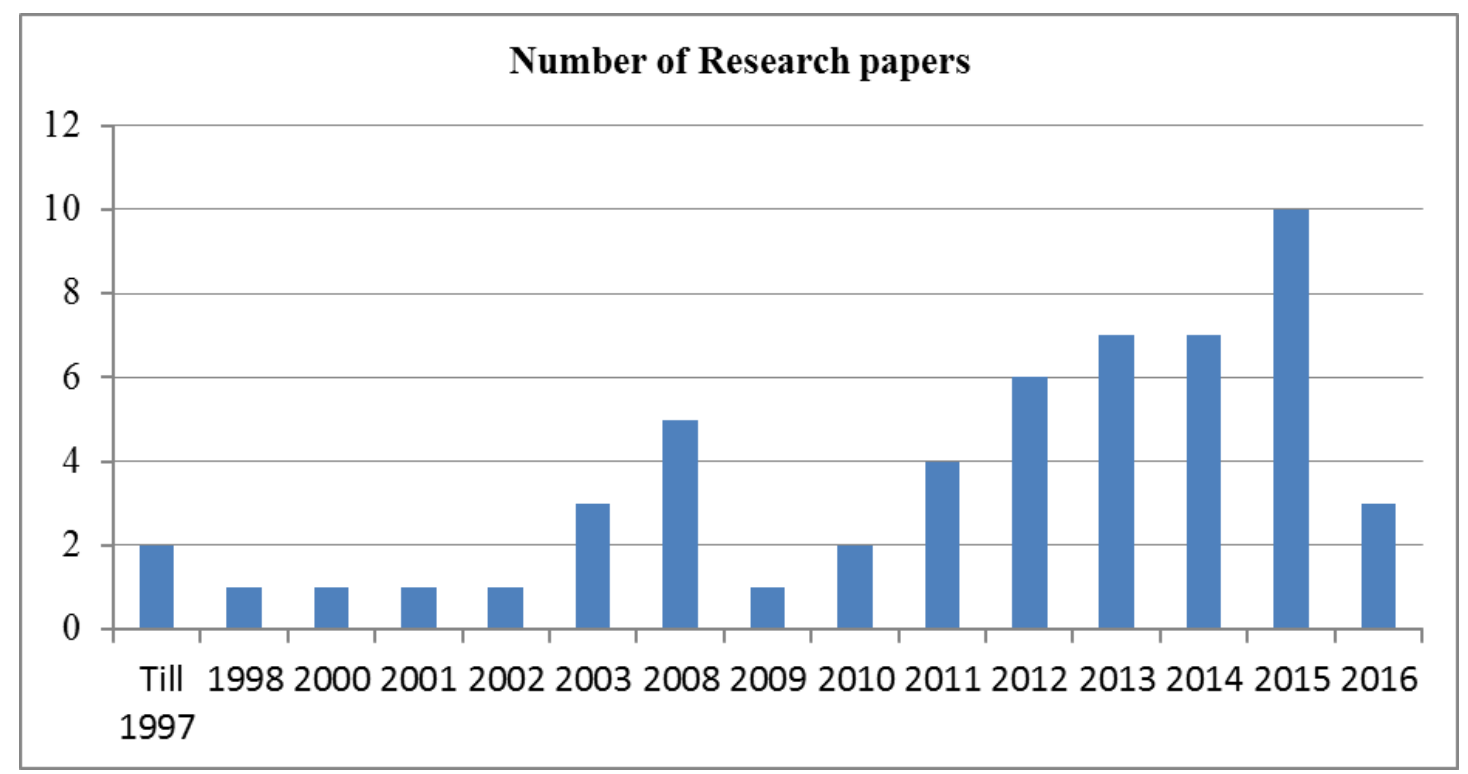

Figure 1 Classification of research papers year wise from top journals 
sales. This technique results in as much as one third of their new sales (Artun and Levin, 2015). Telecom companies scrape through massive volumes of data to predict which customers are most likely to leave them. This helps in designing policies towards customer retention.

\subsection{Five Vs of Big Data}

While the term "big data" is relatively new, the act of gathering and storing large amounts of information for eventual analysis is ages old. The concept gained momentum in the early 2000s when industry analyst Doug Laney articulated the now-mainstream definition of big data as the three Vs - Volume, Velocity and Variety. With further refinement, big data is now characterized with five V's as summarized in Table 1 below.

Table 1 Five V's of big data
\begin{tabular}{|l|l|}
\hline \multicolumn{1}{|c|}{ Characteristics } & \multicolumn{1}{c|}{ Description } \\
\hline Volume & $\begin{array}{l}\text { Large amount of Data in terabytes or } \\
\text { petabytes has been doubling every } \\
\text { forty months (Davenport, 2014) }\end{array}$ \\
\hline Velocity & $\begin{array}{l}\text { Rate of Data accumulation is } \\
\text { increasing in every business or } \\
\text { organization }\end{array}$ \\
\hline Variety & $\begin{array}{l}\text { There are multitude of Data Sources } \\
\text { like enterprise systems, social media, } \\
\text { text, video, audio, email, RFID, web } \\
\text { applications and other digital devices. }\end{array}$ \\
\hline Veracity & $\begin{array}{l}\text { Quality of Data is very essential for } \\
\text { the accuracy of decision. }\end{array}$ \\
\hline Value & $\begin{array}{l}\text { Economic \& Social Outcomes can be } \\
\text { improved by obtaining value from the } \\
\text { heterogeneous data. }\end{array}$ \\
\hline
\end{tabular}

Reputed data analytics firm SAS considers two additional dimensions such as Variability and Complexity when it comes to big data.

Variability - In addition to the increasing velocities and varieties of data, data flows can be highly inconsistent with periodic peaks. Is something trending in social media? Daily, seasonal and event-triggered peak data loads can be challenging to manage, even more so with unstructured data.

Complexity - Today's data comes from multiple sources, which makes it difficult to link, match, cleanse and transform data across systems. However, it's necessary to connect and correlate relationships, hierarchies and multiple data linkages or your data can quickly spiral out of control.

\subsection{Different Sources of Big Data}

In addition to traditional information systems, big data originates from different sources such as social network sites, cloud applications, software, social influencers, Data warehouse appliances, public, network technologies, legacy documents, business applications, meteorological data and sensor data. Few sources are explained below.

\section{A. Transactional data}

Transactional data coupled with statistical tools such as regression analysis and decision tree can help in defining a model to predict an outcome such as sales forecast or level of success of a new product launch. The model can take inputs of past data and predict dependent variable. These models can easily be created using statistical tools like SPSS or SAS. All the past data with independent variables is known as transactions and keeping a track on these transactions is mainly referred as 'Transactional Processing System'. The main purpose of Transaction Processing System is to capture the information and update the data for the operational decisions in an organization. There are two ways to process transactions namely Batch processing which processes the data as a single unit over a period of time and Real Time Processing System where data are processed immediately. Both the methods are helpful for making operational decisions in any organization.

\section{B. Social media data}

Popularity of social media in recent years is leading to information getting collected at every possible location in the world. Events are getting reported as they occur. Netizens are happy to share their views, product or service feedback, movie reviews within minutes on Facebook, twitter or WhatsApp. This provides a unique opportunity for decision makers to gather market intelligence. People share their information through social media which helps customers to make purchasing decisions by having a glance at the feedback, customer complaints and miscellaneous services provided with a product. Sentiments of the consumers are also expressed on social media which help companies to make production decisions. Social media Analytics is also used for gathering competitive intelligence about the firm's product and services offered by the competitors in any particular market segment. This also promotes new business ideas for improving the business life cycle. Therefore, the social media data are very essential in making marketing decision at strategic, operational and tactical level.

\section{Internet Applications}

With evolution of internet, millions of users are surfing through various websites generating high volumes of click streams, web searches for products or services. There are numerous online ecommerce websites (such as Amazon, Flipkart, Alibaba, eBay, Paytm, bookmyshow.com etc.) search engines (Google, Yahoo, Bing, etc.) or online banking applications where millions of users are logging in daily and using them. During their searches or transactions various click streams and logs get generated which could be of value.

\section{Data from electronic instruments}

There are numerous electronic media such as smart phones, RFID tags, GPS Sensors, machines connected to networks, scanners, cameras which generate high volumes of datasets. These are other sources of big data.

\subsection{Big Data Analytics}

Big data analytics has emerged as an important tool for supporting managerial decision making. Dyché (2014) suggests that big data discovery efforts can reveal previously unknown findings which can result in insights that are helpful for managerial decision making. Before the invention of computers, people were limited in their ability to store and process data. There were experts who used to make decisions 
on the basis of their intuitions. These intuitions were not always perfect as huge data collection was not possible (Duan and Xiong, 2015). In the present era, big data has led to volume, velocity and variety of data. This has made it easier to analyze the data in terms of statistical reliability and improvement of models (Chen et al., 2012); Big data Analytics is used in making decisions in e-commerce, egovernment, politics, science, technology, health, security and public safety through database segmentation, graph mining, social network analysis, text analytics, web analytics and sentiment affect analytics, criminal network analysis, cyber-attack analysis, multilingual text analysis, health analytics and patient network analysis.

Multi criteria decision making tool also helps in decision making in health industry in order to understand the complete evaluation process by providing a decision support tool (Venkatesh et al., 2010). RFID are introduced for data warehouse which could be integrated in terms of logic and operations (Zhong et al., 2015).

Big data analytics has a significant effect on business value and firm performance leading to savings, reduce operating costs, communication costs, increase returns improve customer relations and developing new business plan.

Big data analytics constitute of advance analytic techniques to operate big data sets. Advanced Analytics prepares big data for making intelligent decisions by the users (Russom, 2011). The analysts compare the historic data from the data warehouse which leads to making better decisions. Big data analytics is not just about data volume but it deals with data variety. According to a research report by Russom (2011) it has been found that there is a very few percentage of the population who are aware of the terms like predictive analytics, advance analytics and big data analytics. RDBMS, data warehousing, data mining, clustering, association, OLAP, BPM, ETL, regression, classification, analysis, genetic algorithm, multivariate statistical analysis and heuristic research are the tools for big data analytics. Big data provides a great benefit for making decisions by providing beneficial data to customers, providing benefits to the business analytics and specific analytic application. In spite of the benefits there are few barriers in the use of big data analytics for making decisions. These barriers generally include inadequacy of staff for handling the advanced analytics for decision making, lack of business support and the problems that frequently arises with the database software.

\subsection{Classification of Analytics}

In general analytics can be classified into 3 categories based on the purpose of use - descriptive, predictive and prescriptive. Descriptive analytics explains a phenomenon from past data through reports, dashboards, which helps in understanding what has happened. Predictive analytics helps us to understand what can happen. It supports predictions based on past data, correlations between variables and patterns. Prescriptive analytics is another powerful tool that supports executive decision making. It helps to understand different outcomes under different scenarios. It consists of various tools such as optimization, simulations, what-ifanalysis scenarios with change in input set of parameters.
Managers can make a decision with proper understanding of expected outcomes and plan contingency in advance.

Data sources play an important role in the way it can be used for analysis. Analytics can be further classified into Text, Audio Video, Web or Network analytics based on source of data. In the following section, we discuss these in detail.

\subsubsection{Text Analytics}

Document representation, enterprise search system, search engines, user models, relevance of feedback, query processing', billions of searches of customer for a particular product on google, searches on Amazon's website provide indicator of intention to purchase the product by customer. Amazon, Jet Airways many other ecommerce firms use this feature to recommend products or flights when next time customer will be browsing their website, thereby improving the probability of customer purchase decision.

\subsubsection{Audio and Video Analytics}

Audio analytics takes seconds to process audio through technology mainly for safety purpose in any organization and can track a wide range of sound in the environment. Video analytics is used to process and analyze videos from variety of fields and industries. This helps in extracting events helpful for taking operational decisions.

\subsubsection{Web Analytics}

Online retailer Amazon uses data mining techniques to mine the big data such as click streams, web searches, order history, online etc. to derive intelligence. This intelligence is used to make decisions about product promotions and it is working successfully for companies such as Amazon. A correlation is derived between previous purchase history and potential new purchase based on similar purchases in the past. This correlation is used to identify potential customers and promote different products to these customers using digital media such as emails, Facebook or by flashing messages on Amazon.com.

\subsubsection{Network Analytics}

Network analytics provides information about devices which are connected to network and how they are interacting with each other. This information helps in designing network policies, to make actionable decisions that help in improving business performance and reducing costs.

\subsection{Technology for Big Data Analytics}

Due to increasing competition in business, there is need for rapid information and data analysis. Rapid data analysis results in better understanding and hence leads to better decision making (Schläfke et al., 2012). Technology is helping to use analytics for predicting the level of risks for disease and infection. Shein (2012) reported that big data can be a great tool in making decisions in medical field. The hospital collects data from electronic devices that monitor the premature babies. There is a huge amount of data which cannot be analyzed by human beings. So, the role of technology can be seen here. Structured data looks for patterns that predicts the onset of diseases and reduces the stay of a person in a hospital. New algorithms can also correlate a patient's behavior change to infection. 


\section{ROLE OF BIG DATA IN DECISION MAKING}

In the current era, business executives are challenged with high expectations from customers, high competition, rising costs of labor and materials and shorter product lifecycles. Globalization is blurring the boundaries among nations. Location and distance from the market are no longer barriers to access the markets. In such a volatile environment, firms need to continuously scan for risks and opportunities and make business decisions quickly based on available data. In this section, we discuss the role of traditional "small data" as well as "big data" for making business decisions.

\subsection{Traditional decision support systems}

Traditional decision support systems supported internal business decisions based on data generated by transactions processing systems such as ERPs (Davenport \& Dyché, 2013). Further evolution led to addition of similar systems on supply and demand side (SRM and CRM). These systems helped to integrate internal operations of the firm with their business partners such as suppliers (e.g. Ariba) and customers (e.g. Siebel). All these systems used well defined structured data in relational databases. Internal operational and tactical decisions were made from these decision support systems (such as how to price the products for optimizing sales, status inquiry of orders, inventory planning, cost analysis, outstanding balance payments according to their due dates etc.). This information helped in accuracy and speed of internal decisions. Traditional data sources provided inputs to data warehouse and data mining operations. Overall architecture included core transaction database, data warehouse which stores extracted data, classifies that data into smaller databases. Further data mining tools provide business intelligence from these datasets. Data mining from accumulated data helped to analyze and identify patterns, correlations or association rules (Han et al., 2011).

\subsection{Benefits of Using Big Data in Decision Making}

In the last few years, with advent of big data, the information requirements of executives have changed. In addition to traditional datasets described above, there are large datasets coming from variety of sources in structured, semi-structured or unstructured forms. There are several ways in which firms can tap value from these datasets to make strategic, tactical and operational decisions.

Business transaction data when mined for association rules provide key insights for decision makers about products bought together or predicting demand for certain items. Getting an understanding of patterns helps retailers such as Wal-Mart to redesign their isles and placement of products together leading to improved sales (Shaw et al., 2001). Prediction of demand for certain items, helps in improved planning ahead of major natural disasters like hurricanes (Shaw et al., 2001). Analysis of terabytes of data coming from aircraft engine provides indicators of part failures thereby improving maintenance as well as safety (Dyche, 2014). Table 2 below summarizes, how big data driven insights lead to information, prediction and actionable decisions.

Table 2 Role of big data in making decisions

\begin{tabular}{|c|c|c|c|}
\hline Big data source & Big data driven Insights & Actionable Decisions & Reference \\
\hline $\begin{array}{l}\text { Google search for a } \\
\text { product or brand }\end{array}$ & $\begin{array}{l}\text { - Customer intention to buy a } \\
\text { particular product } \\
\text { - Identify customer preference for a } \\
\text { particular brand }\end{array}$ & Predicting demand for product & \\
\hline $\begin{array}{l}\text { Google search by } \\
\text { specific key words }\end{array}$ & $\begin{array}{l}\text { What particular information citizens } \\
\text { are looking for or concerned about }\end{array}$ & $\begin{array}{l}\text { Predict spread of flu by geography } \\
\text { by regions }\end{array}$ & $\begin{array}{l}\text { Mayer-Schönberger \& } \\
\text { Cukier, } 2013\end{array}$ \\
\hline Amazon search & $\begin{array}{l}\text { Customer intention to buy a particular } \\
\text { product }\end{array}$ & $\begin{array}{l}\text { Reminder to customer next time } \\
\text { she/he visits the site leading to } \\
\text { chances of sale }\end{array}$ & Amazon.com website \\
\hline $\begin{array}{l}\text { Amazon Purchase } \\
\text { history }\end{array}$ & $\begin{array}{l}\text { Using association rules mined from } \\
\text { billions of records, identify which } \\
\text { different products are bought by } \\
\text { customers }\end{array}$ & $\begin{array}{l}\text { Product recommendation } \\
\text { (customer who bought this also } \\
\text { bought) }\end{array}$ & Amazon.com website \\
\hline Walmart POS data & $\begin{array}{l}\text { - Using association rules mined } \\
\text { from billions of records, identify } \\
\text { which products customers buy } \\
\text { together (market basket analysis) } \\
\text { - Facing disaster such as } \\
\text { hurricanes people buy some } \\
\text { unusual things like pop-tarts etc. in } \\
\text { addition to usual water, batteries, } \\
\text { shovels etc. }\end{array}$ & $\begin{array}{l}\text { - Store layouts redesign to place } \\
\text { such products together } \\
\text { - Inventory planning based on } \\
\text { buying patterns prior to } \\
\text { disasters such as hurricanes }\end{array}$ & $\begin{array}{l}\text { - Waller \& Fawcett, } 2013 \\
\text { - } \quad \text { Dyché, } 2014\end{array}$ \\
\hline
\end{tabular}


Table 2 Role of big data in making decisions (Con't)

\begin{tabular}{|c|c|c|c|}
\hline $\begin{array}{l}\text { Competitive } \\
\text { intelligence from social } \\
\text { media }\end{array}$ & $\begin{array}{l}\text { Comparative analysis between } \\
\text { competing products }\end{array}$ & Plan product strategy & Vries et al.,2016 \\
\hline $\begin{array}{l}\text { Data from telematics } \\
\text { sensors used by UPS } \\
\text { vehicles }\end{array}$ & $\begin{array}{l}\text { Information about speed, routes, } \\
\text { direction, braking, drive train } \\
\text { performance }\end{array}$ & $\begin{array}{l}\text { Redesign Routes leading to saving } \\
\text { of millions of gallons of fuel }\end{array}$ & Davenport \& Dyché, 2013 \\
\hline $\begin{array}{l}\text { Call center logs, online } \\
\text { usage of accounts }\end{array}$ & $\begin{array}{l}\text { Create complete profile for } \\
\text { customer journey }\end{array}$ & $\begin{array}{l}\text { Design future strategies for } \\
\text { improved customer service }\end{array}$ & Davenport \& Dyché, 2013 \\
\hline
\end{tabular}

\subsubsection{Understanding Customer Journeys}

Leading banks such as Wells Fargo, Bank of America and Discover get to understand their customer relationship using big data gathered through variety of sources as described in Figure 2 below. They create complete profile of customer journey's using mix of structured, semi-structured and unstructured data originating from call center logs, website clicks, transaction records, ATM transactions, clickstreams etc. This profile helps them to understand reasons for customer attrition, correlating journeys with customer opportunities and problems (Davenport \& Dyché, 2013).

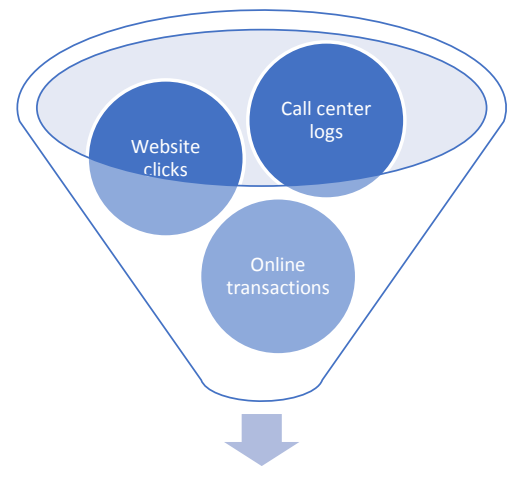

Profile of Customer Journeys

Figure 2 Customer journey

\subsubsection{Competitive Intelligence}

There are several studies conducted to understand consumer sentiments, attitudes and opinions using social networking sites (SNSs). In addition to consumer sentiment about their own products, business executives need to know what customers think about competitor's products. This intelligence will help to plan innovations in future products or design a strategy to market the products. Mining of a social media data can obtain comparative analysis of consumer opinions and sales performance of a business and its competitors.

Similarly, trends analysis provided by google provides a good mechanism of comparing product searches of two or more competing products. These analytics provides insights on how different products, services or persons are being searched over the web in different geographies. This can provide valuable intelligence regarding product awareness and designing future marketing strategies or new product launches. There are websites such as sentiment140.com which provide glimpse of possible ways in which this intelligence can be tapped.

\subsubsection{Cost and Time Reduction}

There are numerous opportunities of cost and time reduction using big data. Big data technologies such as Hadoop clusters are emerging as significantly low-cost option compared to traditional databases. It can play a role in real time decisions regarding promoting offers and services to customers based on their current locations. UPS saves millions of dollars in fuel by collecting, analyzing data from telematics sensors installed on its 46,000 vehicles and redesigning its vehicle routes using this large dataset (Davenport \& Dyché, 2013).

\subsubsection{Optimization and Simulations of Supply Chains}

Supply chains are getting increasingly complex with multitude of suppliers and business partners. Over last two decades, members of supply chain have implemented enterprise systems which record every transaction. With advancement of EAI information sharing happens between business partners such as suppliers and customers. For efficient movement of goods across supply chains, technology plays an important role. Scanning devices such as sensors and RFID, location tracking devices like GPS, video recordings etc. - all these churn large volumes of data with inventory movement. Supply chain analytics enhances capability of decision makers by getting an integrated view of the data within supply chain. We can extract, transform, analyze data from data sources within supply chain system and run analytics to derive intelligence. Supply chain analytics provide several advanced capabilities such as dashboards, pattern and trend analysis, drill down views, forecasts, knowledge base, scenario and what-if analysis, simulations and optimization capabilities. These enhance decision making capabilities and interpretations of situations which is very crucial for firms in competitive business environments (Nair, 2012).

\subsubsection{Predicting Future Outcomes}

There are several opportunities of using datasets for predicting future outcomes. Analytics frameworks can be developed to analyze different datasets and make predictions as listed below-

a) Based on historical transactional data, using forecasting models such as regression predict future sales for the product or services for a firm.

b) Based on correlations found in historical purchases, identify products purchased together by customers. Referring to these correlations and purchase history of a customer, predict which products a customer is most likely to buy and make online recommendations. (Artun \& Levin, 2015) 


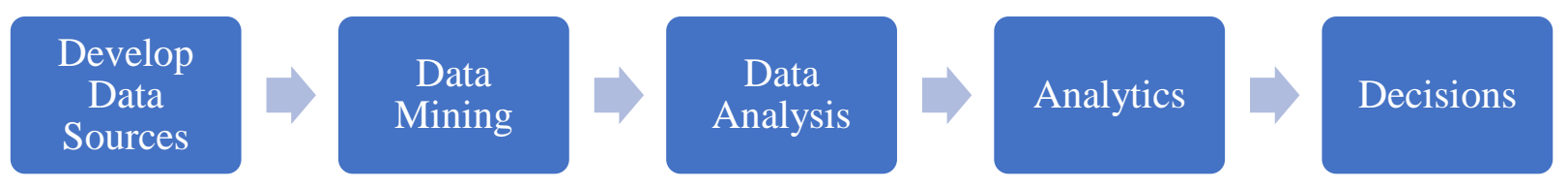

Figure 3 Conceptual framework on big data and decision making

Analyze historical data, study patterns of customer attrition from the past data and identify which variables contribute to customer attrition. Predict which customers are most likely to leave, take proactive steps to retain them. (Artun \& Levin, 2015)

There are many more applications of predictive analytics such as predicting which customers are most likely to buy which products based on their historical purchases. Also, based on Google searches, outbreak of diseases in certain geographic locations can be predicted.

\subsubsection{Real-time Decision Making}

Several visionary companies have developed real-time decision-making capabilities using supply and demand side information. Using analytics, they have online real-time decision-making capabilities that cannot be matched by traditional business models. Transport service providers such as Uber uses big data for real time routing of cars to minimize pick up times and optimize customer experience of a ride (Woodie, 2015). Ola and Uber provide real-time information to both customer and cab driver on Google map. They receive continuous stream of high volume cab demand data and availability of cabs in different geographic areas. They come up with demand management strategies based on realtime demand information. City of Singapore has recently introduced a demand driven, shared private transportation concept enabled by data analytics and mobile technology called as Beeline. This system uses crowd sourced travel patterns, transportation data to identify potential travel routes and dynamically allocates buses to routes based on demand patterns. This reduces travel time for commuters and increase use of shared transport services (Askari, 2015).

\section{CONCEPTUAL FRAMEWORK ON BIG DATA AND DECISION MAKING}

In this section, we describe conceptual framework for firms which would like to develop analytics practices for their business to support business decisions in different areas. Driven by the objectives and the literature, conceptual framework in Figure $\mathbf{4}$ has been designed. As described in earlier section, several leading companies are practicing analytics in one or more aspects of their business. There are still several small and medium size firms which have yet to adopt analytics for gaining competitive advantage. We have developed a framework for such firms to bring analytics into their mainstream business practice. We recommend that once analytics practice is established in the company, this function can be headed by a senior executive. This will ensure that critical insights gained from data analysis are used for decision making. Further, analytics can be incorporated in performance measurement system such as balanced scorecard, real-time dashboard or KPIs.

From the literature review, authors have explored different ways in which big data plays critical role in analytics which in turn provide insights for decision making. Figure 3 clearly depicts the path from big data to decision making. The constructs have been discussed in detail below. The conceptual framework shown in Figure 3 depicts a relationship between five constructs.

\subsection{Develop data sources}

Data sources include traditional data sources such as enterprise systems, customer data, supplier data, social media data, logistics trajectory etc. As a first step, firm needs to have information systems infrastructure and processes in place to collect data through variety of sources based on its business model. For example, a products company focusing on designing new products and assembling them will collect data related to supply, distribution and logistics. A logistics company will collect data related to its fleet movement, packages and routes etc.

\subsection{Data Mining}

Data mining is a process of discovering patterns in large datasets using various statistical techniques, computer programs and database systems. It helps in getting meaningful information from the data. Once data sources are established, based on analytics requirements from different departments, data warehouse will be developed to store multi-dimensional data for query and analysis purpose. Mining these datasets helps in finding previously unknown patterns, correlations and association between different variables.

\subsection{Data Analysis}

Having large volumes of variety of datasets are necessary but not sufficient. Firm needs to develop capability in analytics to get insights from the data. Firm needs to develop a team of analytics professionals with several interdisciplinary skills in the team- a) knowledge and experience in statistics tools such as R software, SPSS, SAS etc. b) programming knowledge c) domain knowledge about the business processes d) data management skills in SQL e) experience in data analysis. With help of domain knowledge and data analysis various opportunities of analytics projects can be identified.

\subsection{Analytics}

As described earlier, firms can take advantage of three types of analytics - descriptive, predictive and prescriptive. Firm can develop their requirements based on opportunities of acquiring new customers, retention of existing customers or identifying risks for its business. Business analytics uses 
a set of principles, statistical tools and computer algorithms to extract knowledge from the data. IBM, SAP, Oracle, SAS, SPSS and R software have already developed tools for data analysis and model development. Hadoop provides framework for developing model from different data sources.

\subsection{Decision Making}

Business analytics is emerging as a potential tool for enterprises to improve their business performance in terms of customer service, customer retention and acquisition. Predictive analytics helps us to predict what can happen based on certain available information. This gives a competitive advantage for a firm to plan ahead. Patterns from data, correlations and associations are helpful for improving sales performance, identifying right customers for products or segmenting markets. Analytics has applications in every domain where data can be collected. Supply chain analytics are available in the areas of inventory optimization, procurement planning, demand forecasting, fleet and route sizing and optimization (Nair, 2012). Social media data provides competitive intelligence, new product ideas and reviews of existing product - crucial information helpful to decide next strategies (Bell, 2012). Big data discovery can provide startling and highly actionable findings (Dyche, 2014). Main goal of data science is to improve ability of managers to make better business decisions (Provost and Fawcett, 2013). Leading companies such as Amazon, WalMart, Google or Netflix have mastered the art of using data and analytics as a tool for predictions, simulations or sometimes for just getting insights. Amazon and Wal-Mart use analytics for decision making in all aspects of conducting their business right from generating demand to managing their supply chains efficiently.

\section{CONCLUSION AND FUTURE RESEARCH DIRECTIONS}

We have come a long way since information revolution has changed the way business firms work. Big data is helping firms to get competitive advantage using different analytics techniques. These techniques help us to get insights, patterns, correlations and associations which could not be understood through traditional small data. These support decisions making process for business executives with the help of social media data, competitive intelligence, cost and time reduction strategies, supply chain analytics, web analytics etc. Firms which recognize significance of big data and developing products around data have received huge dividends in recent years. Many firms use analytics in almost all aspects of conducting their business to reap the benefits of analytics based decision making. In this paper, we present a conceptual framework for developing analytics capabilities and how this emerging knowledge can be help small and medium firms to compete using lesser resources. It can be adopted by such companies with changes in line with their business domain and model. This framework can be a starting point for further analysis, enhancement and future research opportunities.

With continued digitization of every aspect of society as well as business, pace of generation of high speed high volume data is going to continue. This provides a sound opportunity to exploit the field of analytics for decision making in different business domains. There are several unique research opportunities in different business, scientific and government domains wherever data is generated continuously.

\section{REFERENCES}

Artun, O., \& Levin, D. (2015). Predictive Marketing: Easy Ways Every Marketer Can Use Customer Analytics and Big Data. John Wiley \& Sons.

Askari Z. (2015). TelecomDrive.com. Smart City Lessons from Singapore - How 'Beeline' is Redefining Transportation from http://telecomdrive.com/smart-city-lessons-from-singaporehow-beeline-is-redefining-transportation/ Accessed on July 23, 2016

Ballé, M. (1998). Transforming decisions into action. Career Development International, 3(6), pp. 227-232.

Boyd, D. and Crawford, K. (2012) 'Critical questions for big data: provocations for a cultural, technological, and scholarly phenomenon', Information, Communication \& Society, 15 (5), pp. 662-679.

Canel, C., \& Das, S. R. (2002). Modeling global facility location decisions: integrating marketing and manufacturing decisions. Industrial Management \& Data Systems, 102(2), pp. 110-118.

Chen, H., Chiang, R. H., \& Storey, V. C. (2012). Business Intelligence and Analytics: From Big Data to Big Impact. MIS quarterly, 36(4), pp. 1165-1188.

Coursaris, C. K., van Osch, W., \& Balogh, B. A. (2016). Informing Brand Messaging Strategies via Social Media Analytics. Online Information Review, 40(1), pp. 6-24.

Davenport, T. H., \& Dyché, J. (2013). Big data in big companies. International Institute for Analytics.

Davenport, T.H. (2014) 'How strategists use 'big data' to support internal business decisions, discovery and production', Strategy \& Leadership, 42 (4), pp. 45-50.

De Vries, N. J., Arefin, A. S., Mathieson, L., Lucas, B., \& Moscato, P. (2016). Relative Neighborhood Graphs Uncover the Dynamics of Social Media Engagement. In Advanced Data Mining and Applications: 12th International Conference, ADMA 2016, Gold Coast, QLD, Australia, December 12-15, 2016, Proceedings 12 (pp. 283-297). Springer International Publishing.

Duan, L., \& Xiong, Y. (2015). Big data analytics and business analytics. Journal of Management Analytics, 2(1), pp. 1-21.

Dubey, R., Gunasekaran, A., Childe, S. J., Wamba, S. F., \& Papadopoulos, T. (2015). The impact of big data on worldclass sustainable manufacturing. The International Journal of Advanced Manufacturing Technology,84 (1-4), pp. 1-15.

Dyche, J. (2000). e-Data: Turning data into information with data warehousing. Addison-Wesley, from https://www.amazon.com/Data-Turning-Data-InformationWarehousing/dp/0201657805 as accessed on 26 July 2016

Dyché, J; ( 2014), Big Data and Discovery, Jills Blog Big Data Digital Innovation, from https://jilldyche.com/2012/12/04/big-data-and-discovery/ as accessed on 14 July, 2016

Fan, J., Han, F. and Liu, H. (2014) 'Challenges of big data analysis', National Science Review, 1 (2), pp. 293-314.

Gareth Bell, I. (2012). Interview with Marshall Sponder, author of Social Media Analytics. Strategic Direction, 28(6), pp. 32-35.

Han, J., Pei, J., \& Kamber, M. (2011). Data mining: concepts and techniques. Elsevier, from https://www.elsevier.com/books/data-mining-concepts-andtechniques/han/978-0-12-381479-1, as accessed on 20 July, 2016

Jeble, S., Kumari, S., Patil, Y. (2016). Role of Big Data and Predictive Analytics. International Journal of Automation and Logistics, 2(4), pp. 307-331 
Ji-fan Ren, S., Fosso Wamba, S., Akter, S., Dubey, R., \& Childe, S. J. (2016). Modelling quality dynamics, business value and firm performance in a big data analytics environment. International Journal of Production Research, 55 (17), pp. 116.

Keeso, A. (2014). Big data and environmental sustainability: a conversation starter. Smith School Working Paper Series, 2014-04. University of Oxford, 2014. Available at $h t t p: / / w w w$. smithschool. ox.

ac. uk/library/workingpapers/workingpaper\% 2014-04. Pdf as accessed on 26 July, 2016

Kitchin, R. (2014). Big data, new epistemologies and paradigm shifts. Big Data \& Society, 1 (1), DOI: $10.1177 / 2053951714528481$.

Mayer-Schönberger, V., \& Cukier, K. (2013). Big data: A revolution that will transform how we live, work, and think. Houghton Mifflin Harcourt. From http://www.amazon.in/BigData-Revolution-Transform-Think/dp/0544227751 as accessed on 29 July, 2016

McAfee, A., Brynjolfsson, E., Davenport, T. H., Patil, D. J., \& Barton, D. (2012). Big data. The management revolution. Harvard Business Review, 90(10), pp. 61-67.

Nair, P. R. (2012). Supply Chain Analytics. CSI Communications, 33(9), pp. 11.

Provost, F., \& Fawcett, T. (2013). Data science and its relationship to big data and data-driven decision making. Big Data, 1(1), pp. 51-59.

Russom, P. (2011). Big data analytics. TDWI Best Practices Report, Fourth Quarter, pp. 1-35.

Schläfke, M., Silvi, R., \& Möller, K. (2012). A framework for business analytics in performance management. International
Journal of Productivity and Performance Management, 62(1), pp. 110-122.

Shaw, M. J., Subramaniam, C., Tan, G. W., \& Welge, M. E. (2001). Knowledge management and data mining for marketing. Decision support systems, 31(1), pp. 127-137.

Shein, Esther; 2012; Data analytics driving medical breakthroughs from

http://www.computerworld.com/article/2502520/healthcareit/data-analytics-driving-medicalbreakthroughs.html?page $=3$ as accessed on 26 July, 2016

Venkatesh, V. G., Dubey, R., Joy, P., Thomas, M., Vijeesh, V., \& Moosa, A. (2015). Supplier selection in blood bags manufacturing industry using TOPSIS model. International Journal of Operational Research, 24(4), pp. 461-488.

Waller, M. A., \& Fawcett, S. E. (2013). Click here for a data scientist: Big data, predictive analytics, and theory development in the era of a maker movement supply chain. Journal of Business Logistics, 34(4), pp. 249-252.

Waller, M. A., \& Fawcett, S. E. (2013). Data science, predictive analytics, and big data: a revolution that will transform supply chain design and management. Journal of Business Logistics, 34(2), pp. 77-84.

Woodie A. (2015). Datanami. How Uber Uses Spark and Hadoop to Optimize Customer Experience Retrieved July 23, 2016 From http://www.datanami.com/2015/10/05/how-uber-uses-sparkand-hadoop-to-optimize-customer-experience/ as accessed on 26 July, 2016

Zhong, R. Y., Huang, G. Q., Lan, S., Dai, Q. Y., Chen, X., \& Zhang, T. (2015). A big data approach for logistics trajectory discovery from RFID-enabled production data. International Journal of Production Economics, 165, pp. 260-272.

Shirish Jeble is currently a faculty at IBS Business School, Pune, India with the Department of IT and Operations. He holds a Masters in Management from University of Mumbai and is currently a PhD scholar at the Symbiosis International University, India. He has over 20 three years' experience that includes both industry and academics. He has over five years of experience of PG teaching and research experience in the area of operations management, supply chain management, lean, information technology and business analytics. His research interests include big data and sustainable business development.

Sneha Kumari is a Junior Research Fellow at Symbiosis International University. She has completed her graduation in Agriculture under Indian Council of Agriculture Research fellowship and her Masters in Agribusiness Management under Indian council of Agriculture Research merit. Currently she is pursuing PhD from Symbiosis International University. She has published few research papers in the area of agriculture, sustainability, technology, climate change and attended several national and international conferences.

Yogesh Patil is Professor and Head - Research Publications at Symbiosis Centre for Research and Innovation, Symbiosis International University, Pune, India. He holds Master and Doctorate from University of Pune, India and has over 16 years of PG teaching and research experience in the area of environmental science, management and technology. His research interests include - waste management, sustainability, climate change, industrial ecology and reverse logistics. He has published over 50 research papers/chapters and successfully completed projects funded by UGC, IFS, Sweden; OPCW, The Netherlands and World Bank. He has received several awards and fellowships. 